\title{
Less invasive fractional flow reserve measurement from 3-dimensional quantitative coronary angiography and classic fluid dynamic equations
}

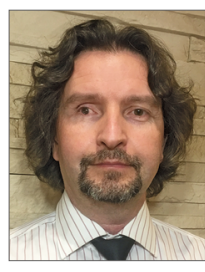

Balazs Tar ${ }^{1}, \mathrm{MD}$; Csaba Jenei², MD; Csaba Andras Dezsi ${ }^{3}, \mathrm{MD}, \mathrm{PhD}$; Sandor Bakk ${ }^{1}, \mathrm{MD}$; Zoltan Beres ${ }^{1}, \mathrm{MD}$; Janos Santa ${ }^{1}, \mathrm{MD}$; Marianna Svab ${ }^{1}$, MD; Veronika Szentes ${ }^{3}, \mathrm{MSC}$; Peter Polgar', MD, PhD; Csaba Bujaky4 ${ }^{4}, \mathrm{MD}$; Daniel Czuriga², MD, PhD; Zsolt Kőszegi ${ }^{1,2 *}, \mathrm{MD}, \mathrm{PhD}$

1. Josa Andras Teaching Hospital, Nyiregyhaza, Hungary; 2. Institute of Cardiology, University of Debrecen Medical Center, Debrecen, Hungary; 3. Department of Cardiology, Petz Aladar County Teaching Hospital, Gyor, Hungary; 4. Heart Center Balatonfüred, Balatonfüred, Hungary

This paper also includes supplementary data published online at: http://www.pcronline.com/eurointervention/141st_issue/167

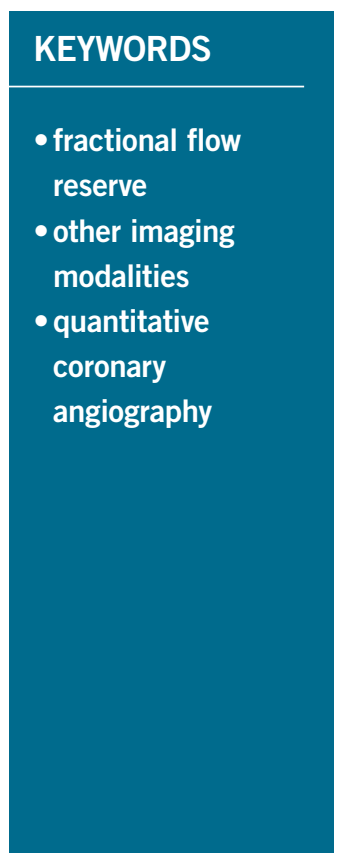

\begin{abstract}
Aims: The aim of this study was to develop a simplified model of FFR calculation $\left(\mathrm{FFR}_{\text {sim }}\right.$ ) derived from three-dimensional (3D) coronary angiographic data and classic fluid dynamic equations without using finite element analysis.
\end{abstract}

Methods and results: Intracoronary pressure measurements were performed by pressure wire sensors. The lumens of the interrogated vessel segments were reconstructed in $3 \mathrm{D}$. The coronary artery volumetric flow was calculated based on the velocity of the contrast material. Pressure gradients were computed by classic fluid dynamic equations. The diagnostic power of the simplified computation of the FFR $\left(\mathrm{FFR}_{\mathrm{sim}}\right)$ was assessed by comparing the results with standard invasive FFR measurements $\left(\mathrm{FFR}_{\text {meas }}\right)$ in 68 vessels with a single stenosis. We found a strong correlation between the $\mathrm{FFR}_{\text {sim }}$ and the $\mathrm{FFR}_{\text {meas }}(\mathrm{r}=0.86$, $\mathrm{p}<0.0001$ ). The sensitivity and specificity for predicting the abnormal FFR of $\leq 0.80$ (indicating haemodynamically significant stenosis) were $90 \%$ and $100 \%$, respectively. The area under the curve (AUC) was 0.96. To achieve $100 \%$ negative and positive predictive values we defined the $\mathrm{FFR}_{\text {sim }}>0.88$ and the $\mathrm{FFR}_{\text {sim }}$ $\leq 0.8$ ranges. In our patient population, these ranges were found in $69 \%$ of the cases.

Conclusions: According to our simplified model, the invasive FFR measurement can be omitted without misclassification in pre-specified ranges of the calculated $\mathrm{FFR}_{\text {sim }}$.

\footnotetext{
*Corresponding author: University of Debrecen Medical Center, Moricz. Zs. krt. 22, 4032 Debrecen, Hungary. E-mail:koszegi@med.unideb.hu
} 


\section{Abbreviations}

3D

three-dimensional

AUC

area under the curve

CFD computational fluid dynamic(s)

DS diameter stenosis

FFR fractional flow reserve

GTN glyceryl trinitrate

IVUS intravascular ultrasound

MLA minimal lumen area

OCT optical coherence tomography

QCA quantitative coronary angiography

\section{Introduction}

Despite the strong recommendation (class I, level A) in the current guidelines for fractional flow reserve (FFR) assessment of angiographically intermediate coronary artery disease in the absence of evident ischaemia, a low adoption rate of this method has been documented ${ }^{1}$. Numerous reports have been published on assessing the ability of the imaging techniques to predict the functional significance of a coronary stenosis, including three-dimensional (3D) angiography ${ }^{2,3}$, intravascular ultrasound (IVUS) ${ }^{4,5}$, optical coherence tomography (OCT) ${ }^{5}$ and coronary computed tomographic angiography (CCTA $)^{6}$. Fluid dynamic computation (CFD) of the pressure gradient has also been proposed recently for calculation of the virtual FFR by using the Navier-Stokes equations from both non-invasive ${ }^{7,8}$ and invasive coronary angiography ${ }^{9,10}$. However, this technique requires a special numerical method called finite element analysis (FEA) for solving problems by subdividing a large problem into simpler parts (i.e., finite elements). The special software package necessary for these calculations is one limitation of its broad availability. In addition to the methods referred to above, other results of extensive research from the past decades have contributed to the optimal treatment of coronary artery patients in the catheterisation laboratory ${ }^{11}$; however, even today various questions remain unanswered.

Our aim in the current study was to develop a simplified model to calculate FFR using anatomical data from 3D coronary angiography with contrast velocity measurement and classic fluid dynamic equations.

\section{Methods}

We investigated 64 patients with intermediate severity epicardial coronary artery disease and without visible collaterals from four centres undergoing coronary angiography and FFR measurement. This was a retrospective evaluation of the results of the FARAO study (Investigation of the Fractional Flow Reserve and the Presence of Collaterals during AdministRation of Adenosin and COntrast Material) (Cardiologia Hungarica. 2014. https://www. doki.net/tarsasag/kardiologia/upload/kardiologia/magazine/1_ TarBalazs.pdf?web_id=8D342826388CAE0). Patients presented with stable angina and angiographically intermediate epicardial coronary artery disease $(40-70 \%$ diameter stenosis) in a main branch of the coronary system with a diameter $>2 \mathrm{~mm}$. Bypass grafts, chronic total occlusions, bifurcation lesions, ostial stenoses and left main (LM) disease were excluded from the analysis.

\section{CORONARY ANGIOGRAPHY AND FRACTIONAL FLOW RESERVE MEASUREMENT}

Diagnostic angiographic pictures were recorded using standard fluoroscopic views on an AXIOM Artis X-ray device (Siemens Healthineers, Erlangen, Germany). Contrast dye was injected in $5 \mathrm{ml}$ fractions with a speed of $3 \mathrm{ml} / \mathrm{sec}$ using the ACIST CVi ${ }^{\circledR}$ Injection System (ACIST Medical Systems, Eden Prairie, MN, USA). If a coronary lesion was deemed intermediate during visual assessment (40-70\% diameter stenosis), then FFR measurement was performed using a RadiAnalyzer ${ }^{\mathrm{TM}}$ device (St. Jude Medical, St. Paul, MN, USA) and a pressure-sensor guidewire (PressureWire $^{\mathrm{TM}}$ Certus $^{\mathrm{TM}}$; St. Jude Medical). After calibrating the wire, pressures were equalised with the sensor positioned at the tip of the catheter. After administering intracoronary (ic.) glyceryl trinitrate (GTN) and flush of saline, the resting pressure curve was recorded. Then, 150-200 $\mu \mathrm{g}$ of ic. adenosine was administered, followed by the contrast injection (Supplementary Figure 1). To document the exact position of the pressure sensor during the measurement, the angiography was immediately recorded at the time of peak hyperaemia. These images were also used for the calculation of the coronary flow velocity by detecting the frame count until the contrast material reached the sensor. In all cases, measurements were performed approximately $2 \mathrm{~cm}$ below the coronary stenosis. If the $\mathrm{FFR}_{\text {meas }}$ was $\leq 0.80$, then the coronary lesion was considered haemodynamically significant and percutaneous coronary intervention (PCI) was performed.

\section{THREE-DIMENSIONAL QUANTITATIVE CORONARY RECONSTRUCTION}

Following invasive measurements, 3D angiographic reconstructions were performed offline, using dedicated software (QAngio ${ }^{\circledR}$ XA Research Edition 1.0; Medis specials bv, Leiden, the Netherlands). During reconstructions, two angiographic recordings of good quality, with at least $25^{\circ}$ difference in angle, were used. We modelled the interrogated vessel segment in $3 \mathrm{D}$, starting from the coronary orifice to the level of the pressure wire sensor.

The software used for 3D reconstruction is commercially available. Our model required 3D imaging to acquire highly accurate anatomical data. Nonetheless, similar software from other manufacturers is also applicable. FFR $_{\text {sim }}$ values were calculated from the corresponding data of the precise anatomical reconstruction.

\section{COMPUTATION OF FRACTIONAL FLOW RESERVE FLOW EQUATIONS}

FFR can be calculated from the overall pressure drop across the vessel measured at the level of the pressure wire sensor, provided that the arterial pressure is known. Efforts have previously been made to determine the pressure drop in a coronary artery stenosis with simple equations describing fluid flow. These have been compared to direct pressure measurements and flow data in 
experimental animal models ${ }^{12,13}$ and human studies ${ }^{14-17}$. During our estimations, we used the simplified equation characterising the circumvented stenosis in the following form (Figure 1).

$$
\begin{aligned}
& -\Delta \mathrm{p}=\mathrm{R}^{*} \mathrm{Q} \\
& -\Delta \mathrm{p}_{\text {laminarflow }}=\left(8 * \pi^{*} \eta * \mathrm{~L} / \mathrm{A}^{2}\right) * \mathrm{Q} \\
& -\Delta p_{\text {flowseparation }}=k_{\text {flowseparation }}{ }^{*} \rho / 0.266 *\left(1 / M L A-1 / A_{\text {distal }}\right)^{2 *} Q^{2} \\
& \text { where } \mathrm{k}_{\text {flowseparation }}=1.21+0.08 *\left(\mathrm{~L}_{\text {lesion }} / 2 * \mathrm{D}_{\text {ref.lesion }}\right) \\
& \rho \text {-blood density }(1,060 \mathrm{~g} / \mathrm{l}) \\
& \eta \text {-blood viscosity ( } 3.5 \text { cPoise) } \\
& \mathrm{L}-\text { lesion length }(\mathrm{mm})
\end{aligned}
$$

Figure 1. The applied fluid dynamics equations. The morphological data $\left(A_{\text {distap }} A_{\text {lesion, }} L_{\text {lesion }}, L\right)$ derived from $3 D$ coronary angiography. To assess volumetric flow $(Q)$, we used an averaged flow velocity. $\Delta p$ : pressure gradient; $Q$ : volumetric flow; $R$ : resistance

\section{ANATOMICAL MODEL}

During our calculations we applied the following anatomical model utilising data from 3D reconstruction (Figure 2).

\section{VOLUMETRIC FLOW DETERMINATION}

To assess volumetric flow (Q), we used an average flow velocity. Blood flow velocity was assumed identical proximal and distal to the stenosis during the time of peak vasodilatation. Volumetric flow was calculated from the average velocity of the contrast dye during maximal vasodilation. This velocity was determined from the distance travelled by the contrast material and its transport time.

Flow of the contrast material has been examined by the TIMI frame count method for a while now ${ }^{18}$. The number of frames between given anatomical landmarks can be used for the characterisation of flow. In order to define "distance" $\left(\mathrm{s}_{\text {contrast }}\right)$ in our model, we used the distal pressure sensor position as a reference endpoint for the measurement of the contrast velocity. The exact length of the vessel segment was determined with the help of 3D reconstruction. Time $(\mathrm{t})$ necessary for travelling a given distance was calculated from the frame rate (15-30 frames/sec) and the number of frames (TIMI framenumber ) displaying contrast flow in the vessel:

$$
\mathrm{t}_{\text {contrast }}=\mathrm{TIMI}_{\text {framenumber }} \times 1 / 15-30 \mathrm{sec}
$$

We applied a standard $3 \mathrm{ml} / \mathrm{sec}$ volumetric speed during the administration of the contrast medium. Flow velocity of the contrast blood, i.e., average flow velocity of the blood in the artery was defined as:

$$
\text { vcontrast }=\mathrm{s}_{\text {contrast }} / \mathrm{t}_{\text {contrast }}
$$

The average velocity and the mean cross-sectional area of a given vessel segment were applied for calculating the average volumetric flow necessary for solving flow equations. We also took into account the different flow distribution present in the proximal and the distal part of the vessel. To this end, we determined the average cross-sectional area for the proximal and the distal segments separately. In addition to providing the minimal lumen diameter, minimal lumen area, reference diameter and area, as well as other morphological parameters, the $3 \mathrm{D}$ reconstruction software is also capable of calculating the average cross-sectional area of a vessel segment of given length. Thus, it does not require an additional step in the calculation.

The volumetric flow calculations are carried out using the standard equations:

$$
\begin{gathered}
\mathrm{Q}_{\text {prox }}=\mathrm{v}_{\text {contrast average }} \times \mathrm{A}_{\text {proximal average }} \\
\mathrm{Q}_{\text {dist }}=\mathrm{v}_{\text {contrast average }} \times \mathrm{A}_{\text {distal average }}
\end{gathered}
$$

This concept applies the assumption of the constant mean velocity $\left(\mathrm{v}_{\text {average }}\right)$ in the target epicardial coronary segment. As side branches are taking off, the volumetric flow rate $(\mathrm{Q})$ will decrease proportionally with the decrease of the cross-sectional area of the distal reference segment $\left(\mathrm{A}_{\text {distal average }}\right)^{19}$.

We demonstrate the algorithm in a representative case (Figure 3). DETERMINING THE CALCULATED FFR (FFR ${ }_{\text {sim }}$ )

Following the substitution of the parameters derived as described in sections I-III into simple flow equations, we calculated the overall

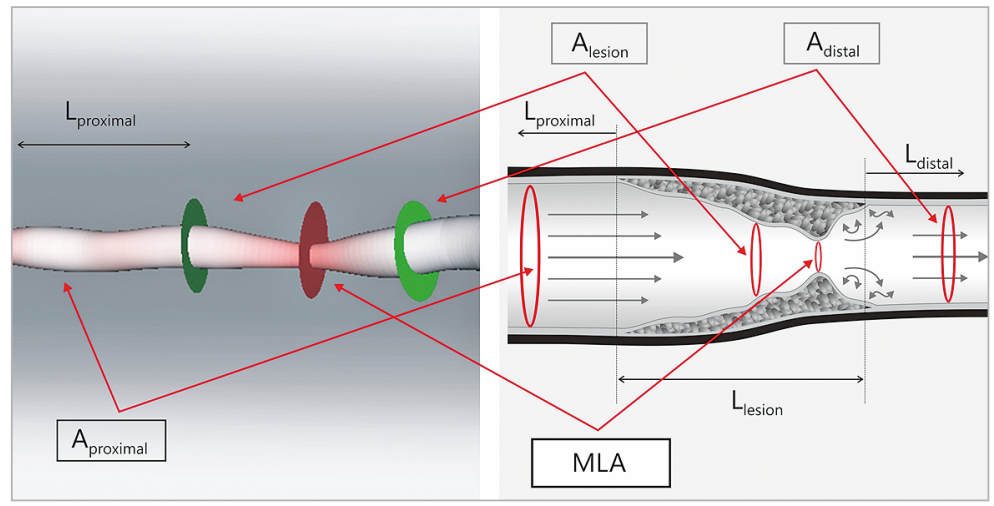

Figure 2. 3D reconstruction and the model of the studied coronary segment. We used the following anatomical parameters to solve fluid dynamic equations. $A_{\text {proximal }}$ : mean area of the proximal part of the coronary artery (from the beginning of the reconstructed vessel to the stenotic segment); $A_{\text {lesion }}:$ mean area of the stenosis; MLA: minimal lumen area; $A_{\text {distal }}$ mean area of the distal part of the studied artery (from the end of the stenosis to the pressure wire sensor); $L_{\text {proximal }}$ : length of the proximal segment; $L_{\text {lesion }}:$ length of the stenosis; $L_{\text {distal }}:$ length of the distal part of the vessel 


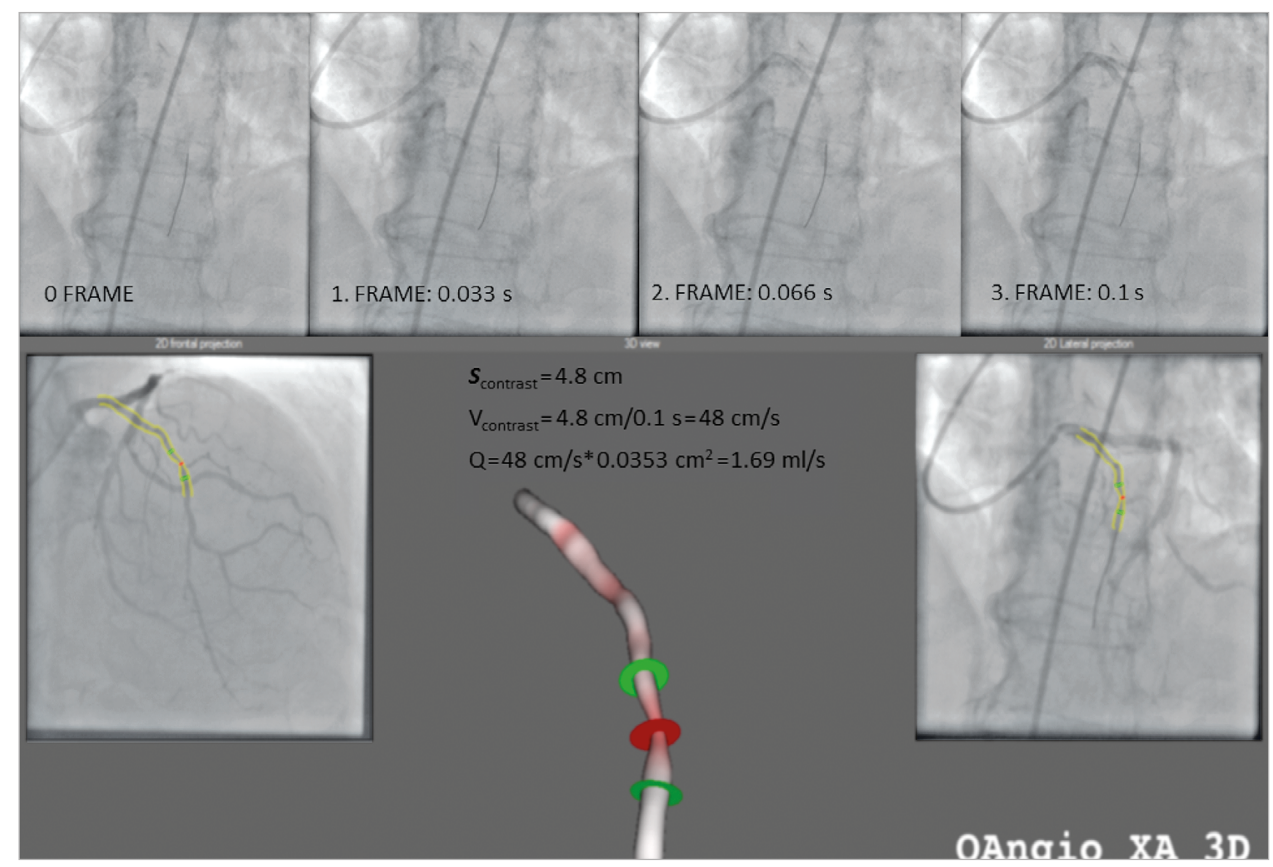

OAncio XA 3D

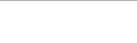

Figure 3. Calculation of volumetric flow $(Q)$ from contrast material flow time and $3 D$ distance. $Q$ : volumetric flow of blood; $S_{\text {contrast }}$ travelled distance of contrast material from $3 D$ reconstruction; $v$ : average velocity of contrast dye

pressure drop across the lesion to the level of the pressure wire sensor. By subtracting the pressure drop from the mean arterial pressure $\left(\mathrm{p}_{\mathrm{a}}\right)$, we determined the calculated distal mean arterial pressure $\left(p_{d}\right)$. The FFR $_{\text {sim }}$ was calculated based on the known formula as follows (Figure 4):

$$
\mathrm{FFR}_{\text {sim }}=\mathrm{p}_{\mathrm{d}} / \mathrm{p}_{\mathrm{a}}
$$

\section{TIME NECESSARY FOR RECONSTRUCTION AND}

\section{CALCULATIONS}

Following the selection of the two runs that characterise the lesion well, the proposed procedure is only prolonged by the time necessary for the $3 \mathrm{D}$ reconstruction process, as pressure gradients can be instantaneously calculated from the simple equations based on some morphological data. The $3 \mathrm{D}$ reconstruction process may be carried out in approximately 3 minutes by a practised examiner, so the method we propose may be considered a truly prompt tool readily available for the interventional cardiologist right next to the operating table. The reading of the frame counts during vasodilatation from the moment the contrast dye enters the target vessel segment till it reaches the distal reference endpoint of the same segment requires approximately one minute.

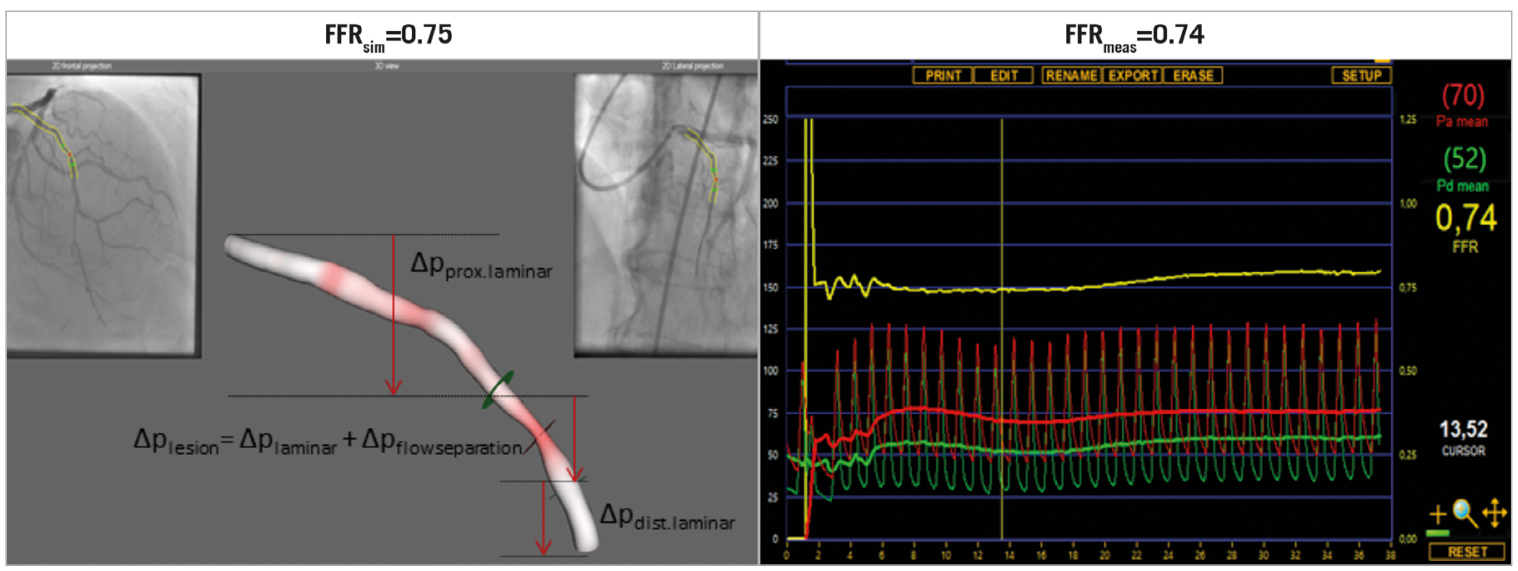

Figure 4. Calculated and measured FFR values. FFR ${ }_{\text {meas }}$ : measured fractional flow reserve; $F F R_{\text {sim }}:$ calculated fractional flow reserve; $\Delta p_{\text {distlaminar }}$ : pressure drop in the distal part of the vessel; $\Delta p_{\text {flowseparation }}$ : pressure gradient because of the flow separation at the exit of the stenosis; $\Delta p_{\text {laminar: }}$ pressure drop because of laminar flow; $\Delta p_{\text {lesion }}:$ pressure gradient of the stenotic lesion; $\Delta p_{\text {prox.laminar }}$ : pressure drop in the proximal segment of the studied coronary artery 


\section{STATISTICAL ANALYSIS}

Continuous variables were expressed as mean $( \pm \mathrm{SD})$, if normally distributed, or as median (with an interquartile range), in cases of non-normal distribution. Categorical variables were expressed as percentages. The correlation between $\mathrm{FFR}_{\text {sim }}$ and $\mathrm{FFR}_{\text {meas }}$ was examined by Spearman's correlation. Agreement between FFR $_{\text {sim }}$ and $\mathrm{FFR}_{\text {meas }}$ was assessed by Bland-Altman analysis. The area under the curve (AUC) by receiver operating characteristic (ROC) analysis was used to assess the diagnostic power of $\mathrm{FFR}_{\text {sim. We }}$ used the Microsoft Excel for Windows programme (Microsoft Corporation, Redmond, WA, USA) for the calculation of FFR, and the MedCalc Statistical Software, Version 14.8.1 (MedCalc Software bvba, Ostend, Belgium) for statistical analysis.

\section{Results}

\section{BASELINE CLINICAL AND LESION CHARACTERISTICS}

A total of 68 lesions with intermediate stenoses from 64 patients were investigated; $51.6 \%$ of patients had a history of prior myocardial infarction and $48.4 \%$ had a prior revascularisation procedure. We examined 68 vessels (44 LAD, $18 \mathrm{Cx} / \mathrm{OM}$ and $6 \mathrm{RCA}$ ). Mean maximal percent diameter stenosis (DS\%), percent area stenosis (AS\%) and minimal lumen area (MLA) by 3D-QCA were $46 \%, 71 \%$ and $1.98 \mathrm{~cm}^{2}$, respectively. Patient characteristics are presented in Table 1.

\section{Table 1. Patient characteristics.}

Clinical characteristics

All patients $(n=64)$

\begin{tabular}{|l|c|}
\hline Male gender & $42(65.6 \%)$ \\
\hline Age, years & $62 \pm 9.8$ \\
\hline Hypertension & $51(79.7 \%)$ \\
\hline Dyslipidaemia & $57(89.1 \%)$ \\
\hline Diabetes mellitus & $17(26.6 \%)$ \\
\hline Chronic kidney disease & $3(4.7 \%)$ \\
\hline Current smoker & $18(28.1 \%)$ \\
\hline History of prior myocardial infarction & $33(51.6 \%)$ \\
\hline History of prior PCl & $31(48.4 \%)$ \\
\hline History of prior CABG & $4(6.2 \%)$ \\
\hline $\begin{array}{l}\text { Data shown as mean ( } \pm \text { standard deviation) or } \mathrm{n}(\%) . \text { CABG: coronary } \\
\text { artery bypass grafting; PCl: percutaneous coronary intervention }\end{array}$ \\
\hline
\end{tabular}

\section{CORRELATION AND AGREEMENT BETWEEN FFR sim $_{\text {AND }}$ FFR $_{\text {meas }}$}

Following normality test, rank correlation analysis was performed. A strong correlation between $\mathrm{FFR}_{\text {sim }}$ and $\mathrm{FFR}_{\text {meas }}$ was found: $r($ rho $)=0.86(p<0.0001)$ (Figure 5). With regard to the measured parameters, the Bland-Altman analysis also showed good agreement with a mean difference of $-0.01 \pm 0.08(\mathrm{p}=0.579)$ (Figure 6).

\section{DIAGNOSTIC POWER OF FFR sim $_{\text {FOR IDENTFYING }}$ HAEMODYNAMICALLY SIGNIFICANT STENOSES}

The diagnostic power of the simplified computation of the FFR $\left(\mathrm{FFR}_{\text {sim }}\right)$ was assessed by comparing the results with standard

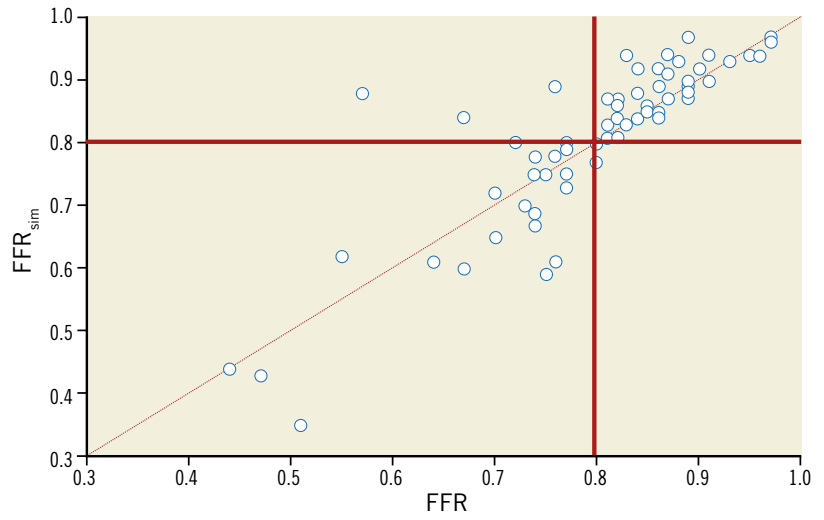

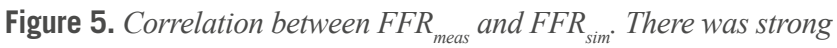
correlation between calculated and measured FFR values $(r=0.86)$. The red lines indicate the diagnostic cut-off point of FFR (0.8).

invasive FFR measurements $\left(\mathrm{FFR}_{\text {meas }}\right)$. Based on ROC curve analysis, the sensitivity and specificity were $90 \%$ and $100 \%$, respectively, for predicting the abnormal FFR of $\leq 0.80$ associated with haemodynamically significant stenoses. Positive and negative predictive values of $\mathrm{FFR}_{\text {sim }}$ were calculated as $100 \%$ and $92.7 \%$, respectively. The AUC was 0.96 (95\% CI: 0.91-1).

To achieve $100 \%$ negative and positive predictive values, we defined distinct ranges of the $\mathrm{FFR}_{\mathrm{sim}}>0.88$ and $\leq 0.8$. In our patient population these ranges were found in $69 \%$ of the cases (Figure 7).

\section{DIAGNOSTIC PERFORMANCE OF FFR sim $_{\text {ASSESSMENT }}$ AGAINST 3D-QCA DATA}

Previous data have repeatedly confirmed higher accuracy of 3D morphological measurements compared to 2D-QCA calculations ${ }^{2}$. Additionally, several authors using the CFD model for FFR calculations reported higher diagnostic accuracy of the calculated FFR when comparing to $3 \mathrm{D}$ morphological data ${ }^{9,10}$. In our study,

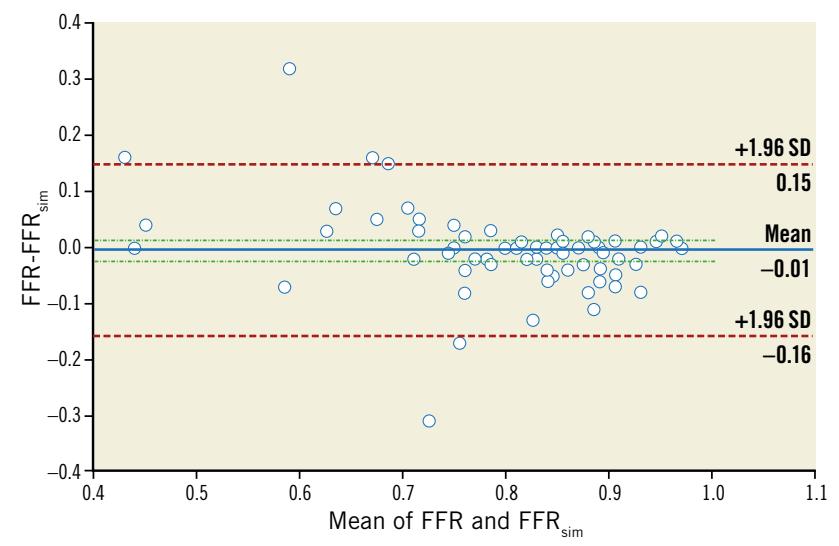

Figure 6. The Bland-Altman plot for the agreement between FFR and FFR ${ }_{\text {sim }}$ showing a mean difference of-0.01 (solid line). The dashed lines represent the values at mean $\pm 2 S D$. 


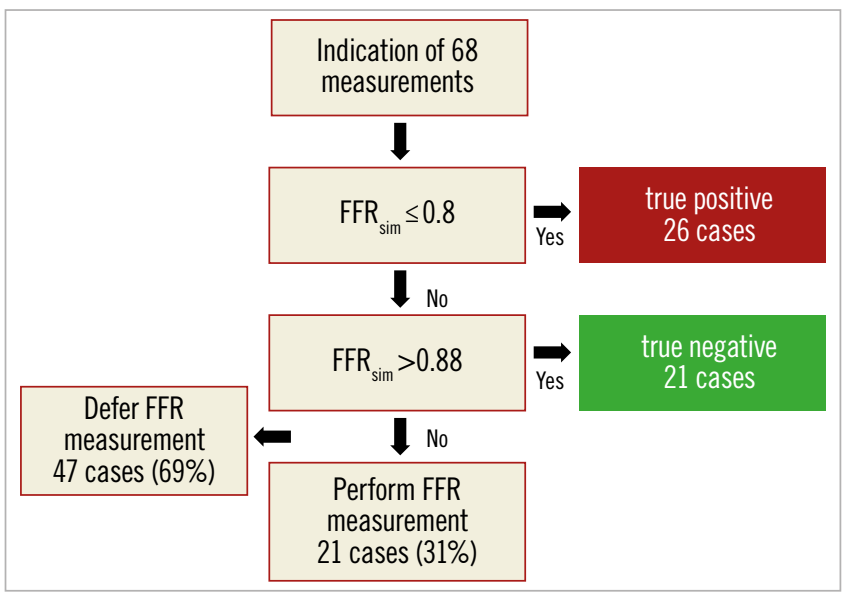

Figure 7. Post hoc analysis of our calculations to defer the unnecessary FFR measurements.

the $\mathrm{FFR}_{\text {sim }}$ showed a stronger association with the measured FFR values than the 3D-MLA and 3D AS\% data (AUC FFR sim $_{\text {vs. }}$ MLA: 0.96 vs. 0.8 [p=0.0065]; AUC FFR ${ }_{\text {sim }}$ vs. AS\%: 0.96 vs. $0.76[\mathrm{p}=0.0005]$ ) (Figure 8, Table 2).

\section{REPRODUCIBILITY OF FFR sim $_{\text {CALCULATIONS }}$}

Following calculation of the primary data set, repeated FFR calculations were carried out for 10 randomly selected stenoses at least one month after the last measurement. These calculations were performed by both the previous investigator and someone familiar with 3D reconstruction technique, who did not know the primary results. The intra-observer variability was $0.00 \pm 0.04$, while the inter-observer variability was $0.01 \pm 0.04$.

\section{Discussion}

Our aim was to develop a simplified model of FFR calculation of intermediate lesions, producing data that are in agreement with the measured FFR. We hoped the model would be adequate to predict the haemodynamic consequences of the significant part of stenoses, obviating the need for invasive measurement. On the other hand, if we could identify cases that really required invasive FFR assessment, the adherence to the pressure wire measurement could be increased and thus the quality of the clinical decision making would improve.

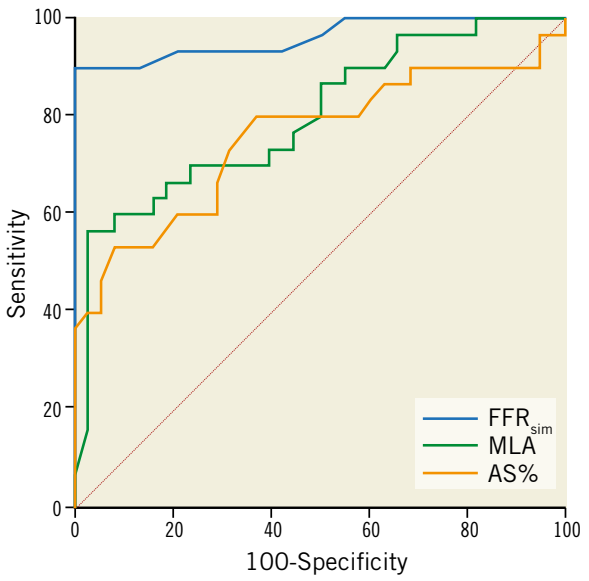

Figure 8. Comparison of ROC curves. The FFR ${ }_{\text {sim }}$ showed a stronger correlation with the measured FFR values than the MLA and AS\% data (AUC FFR sim $_{\text {v. }}$ vLA: 0.96 vs. 0.8 [p=0.0065]; AUC FFR ${ }_{\text {sim }}$ vs. $A S \%: 0.96$ vs. 0.76 [p=0.0005]; AUC MLA vs. AS\%: 0.8 vs. 0.76 $[p=0.46])$. AS\%: percent area stenosis; AUC: area under the curve; $F F R_{\text {sim }}$ : simple (calculated) FFR; MLA: minimal lumen area; $R O C$ : receiver operating characteristic

For calculation of the pressure gradient we used an algorithm that provides the simplest possible data but still sufficiently accurate. In our opinion, this method enables a fast estimation of the pressure gradient.

The pressure-flow relation of the coronary arteries based on experimental models has been proposed for decades ${ }^{12,13}$. Modelling the pressure gradient on a coronary stenosis based on 2D quantitative coronary angiography has also been described ${ }^{14,15}$, but has not penetrated into clinical practice. The limitations of this approach must have originated from the inaccuracy of the $2 \mathrm{D}$ parameters for characterising the $3 \mathrm{D}$ anatomical features of a stenosis and from the fact that the calculations were based on fictive assumed flow conditions instead of real patient specific flow information.

We also used similar fluid dynamic equations as were applied in the early publications, but we incorporated the more accurate 3D anatomical parameters of the lesions and we measured the actual flow velocity in the vessels by the frame count method for the calculation of the translesional pressure gradients.

Table 2. Diagnostic performance of the $\mathrm{FFR}_{\text {sim }}$ and the $3 \mathrm{D}$ anatomic data.

\begin{tabular}{|c|c|c|c|}
\hline Diagnostic performance & $\mathrm{FFR}_{\text {sim }} \leq 0.8$ & 3D-QCA MLA $\leq 1.26 \mathrm{~mm}^{2}$ & 3D-QCA $\%$ AS > 78\% \\
\hline Correlation & 0.86 & 0.56 & -0.55 \\
\hline AUC & 0.96 & 0.8 & 0.76 \\
\hline Sensitivity (\%) & $100(91-100)$ & $57(37-75)$ & $53(34-72)$ \\
\hline Specificity (\%) & $90(73-98)$ & $97(86-100)$ & $92(79-98)$ \\
\hline Positive predictive value (\%) & $88(72-98)$ & $94(71-100)$ & $84(60-96)$ \\
\hline Negative predictive value (\%) & $100(91-100)$ & $76(62-87)$ & $71(57-83)$ \\
\hline
\end{tabular}


The exact assessment of the intracoronary flow is a challenge in clinical practice. Intracoronary Doppler wire examination ${ }^{16}$ or thermodilution measurement by pressure wire sensor - also capable of detecting temperature - was proposed for the evaluation ${ }^{17}$. However, these methods have not reached general availability because of the inherent limitations of their invasive nature, expense and technical difficulties. On the other hand, TIMI frame count can be calculated easily from practically every coronary angiography. It has been used for decades as an estimate of the achieved resting coronary flow velocity during the treatment of myocardial infarction by primary percutaneous coronary intervention $^{18,20}$. We have previously proposed a method for calculating volumetric coronary flow using the TIMI frame count ${ }^{21}$. The clinical utility of the TIMI frame count during adenosine provocation for FFR calculation has also been demonstrated in multicentre studies $^{10,19}$

In our opinion, the proposed $\mathrm{FFR}_{\text {sim }}$ approach could potentially be readily available as a point of care solution to estimate FFR results in the catheterisation laboratory. In its present form, the method does not replace the invasive measurement of the FFR generally, but could serve as an effective pre-screening prior to the pressure wire measurement. Our results show that in $69 \%$ of the cases the invasive measurement could have been obviated based on the calculation of $\mathrm{FFR}_{\text {sim }}$ without any misclassification of the haemodynamic consequence of the stenosis (Figure 7).

\section{COMPARISON OF FFR sim $_{\text {im }}$ TO PREVIOUS MODELS FOR VIRTUAL FFR COMPUTATIONS}

In recent years, combining the CFD model with $3 \mathrm{D}$ reconstruction from invasive angiography has produced some promising results ${ }^{9,10,22-24}$

In the VIRTU-1 study, CFD modelling was performed by the ANSYS CFX software (ANSYS, Inc., Canonsburg, PA, USA) on coronary stenoses of 35 patients. The Navier-Stokes equations were solved for approximately 106 volumetric elements for calculation of the pressure drop. The offline analysis required 24 hours per lesion ${ }^{9}$. In the study of Tu et $\mathrm{al}^{10}$, the calculation time decreased to about 5 minutes by the simplification of the model.

Currently, a number of manufacturers (e.g., Medis, CathWorks) offer software for estimating FFR using the fluid dynamics technique, assumed value of hyperaemic flow and 3D anatomical reconstruction, even without the need for vasodilatation. Instead of further simplification in the solving of the Navier-Stokes equations, in the quantitative flow ratio (QFR) model of Medis, the pressure loss in each $6 \mathrm{~mm}$ subsegment was calculated using the Gould formula. The QFR was derived as follows:

$$
\mathrm{QFR}=\left(\mathrm{Pa}-\int \Delta \mathrm{Pdx}\right) / \mathrm{Pa}^{19} \text {. }
$$

While elaborating our method, we sought to clarify whether the more easily exploitable, swiftly calculable flow equations using the standard parameters of any 3D reconstruction software are accurate enough to estimate the pressure drop developed across the stenosis during hyperaemia. Our findings demonstrate that the model predicts haemodynamically significant lesions with a similar accuracy to previous methods requiring specific software (Supplementary Table 1).

As our calculations require only a simple Excel sheet (Supplementary Figure 2), they can be performed easily by anyone, following a simplified image-based calculation with frame count measurement (provided that $3 \mathrm{D}$ coronary reconstruction is also available, built either in an X-ray machine or in a separate laptop). In our opinion, this simplified method can be incorporated very easily in any Roentgen device equipped with standard 3D reconstruction software.

\section{Limitations}

Validation of the current technique has been carried out in coronary lesions of a medium-sized patient population. The investigations and FFR measurements were executed by several examiners in multiple centres, while the data were later analysed retrospectively in the core centre.

For velocity estimation the TIMI frame count was determined. This method can be used in any coronary angiography; however, its application during vasodilatation requires some routine. We used intracoronary adenosine injection for achieving the maximal vasodilation and the TIMI frame count was calculated from the immediate intracoronary contrast injection. Intravenous adenosine infusion may provide a better opportunity for a proper evaluation of the TIMI frame count; however, the intracoronary adenosine route has the advantage of simplicity, easy repeatability and lower risk of systematic haemodynamic side effects. In addition, the drop of the blood pressure during intravenously provoked vasodilation could affect the coronary flow velocity.

We also tried to take into account the flow distribution present before and after a bifurcation. To this end, we determined the average cross-sectional area for the proximal, the stenosed and the distal segments separately. Therefore, quite reliable volumetric flows were calculated for each segment. Still, this can be considered a limitation of the method.

During the determination of pressure drop, the calculated values were consistently lower than the measured data. We assume that this could have resulted from the lower detectable velocity of the contrast blood, due to the fact that the velocity of the injected contrast dye is generally lower than the blood velocity during vasodilatation. The frame count may also be influenced by the rate of the contrast injection, administered either manually or by power injection.

As we have characterised solely focal lesions while elaborating the current model, further validation is necessary for the characterisation of bifurcation and tandem lesions, as well as diffuse disease.

\section{Conclusions}

Our simplified model developed for the estimation of FFR without direct pressure measurement can help to change our everyday clinical approach from relying predominantly on morphological data to using mainly haemodynamic data. The simplicity and 
promptness of this method could make it suitable for the characterisation of every single intermediate stenosis. As our method has an especially good positive predictive value, it can be safely used to pre-screen those lesions and decide whether or not an invasive FFR measurement is necessary. It seems that in $69 \%$ of the cases the invasive measurement could be omitted on the basis of the calculation of $\mathrm{FFR}_{\text {sim }}$ without any misclassification of the haemodynamic consequence of the stenosis.

\section{Impact on daily practice}

Fluid dynamic computation of the pressure gradient for calculation of the virtual FFR has required the use of sophisticated software. Our new simplified model assesses the functional significance of intermediate coronary artery lesions using only the hyperaemic 3D coronary angiography data. On the basis of the results, the need for application of a pressure wire can be obviated without the risk of misclassification in pre-specified ranges of the calculated FFR sim $_{\text {. }}$.

\section{Acknowledgements}

The authors thank Bela Kezy for his assistance in manuscript translation.

\section{Funding}

Daniel Czuriga was supported by the Janos Bolyai Research Scholarship of the Hungarian Academy of Sciences.

\section{Conflict of interest statement}

The authors have no conflicts of interest to declare.

\section{References}

1. Dehmer GJ, Weaver D, Roe MT, Milford-Beland S, Fitzgerald S, Hermann A, Messenger J, Moussa I, Garratt K, Rumsfeld J, Brindis RG. A contemporary view of diagnostic cardiac catheterization and percutaneous coronary intervention in the United States: a report from the CathPCI Registry of the National Cardiovascular Data Registry 2010 through June 2011. J Am Coll Cardiol. 2012;60:2017-31.

2. Saad M, Toelg R, Khattab AA, Kassner G, Abdel-Wahab M, Richardt G. Determination of haemodynamic significance of intermediate coronary lesions using three-dimensional coronary reconstruction. EuroIntervention. 2009;5:573-9.

3. Kolozsvari R, Tar B, Lugosi P, Santa J, Béres Z, Ungvári T, Polgar P, Köszegi Z. Plaque volume derived from three-dimensional reconstruction of coronary angiography predicts the fractional flow reserve. Int J Cardiol. 2012;160:140-4.

4. Nascimento BR, de Sousa MR, Koo BK, Samady H, Bezerra G, Ribeiro L, Costa MA. Diagnostic accuracy of intravascular ultrasound-derived minimal lumen area compared with fractional flow reserve--meta-analysis: pooled accuracy of IVUS luminal area versus FFR. Catheter Cardiovasc Interv. 2014;84: 377-85.
5. Ma YF, Fam JM, Zhang BC. Critical analysis of the correlation between optical coherence tomography versus intravascular ultrasound and fractional flow reserve in the management of intermediate coronary artery lesion. Int J Clin Exp Med. 2015;8: 6658-67.

6. Wang R, Renker M, Schoepf UJ, Wichmann JL, Fuller SR, Rier JD, Bayer RR 2nd, Steinberg DH, De Cecco CN, Baumann S. Diagnostic value of quantitative stenosis predictors with coronary CT angiography compared to invasive fractional flow reserve. Eur J Radiol. 2015;84:1509-15.

7. Leipsic J, Yang TH, Thompson A, Koo BK, Mancini GB, Taylor C, Budoff MJ, Park HB, Berman DS, Min JK. CT angiography (CTA) and diagnostic performance of noninvasive fractional flow reserve: results from the Determination of Fractional Flow Reserve by Anatomic CTA (DeFACTO) study. AJR Am J Roentgenol. 2014;202:989-94.

8. Li S, Tang X, Peng L, Luo Y, Dong R, Liu J. The diagnostic performance of CT-derived fractional flow reserve for evaluation of myocardial ischaemia confirmed by invasive fractional flow reserve: a meta-analysis. Clin Radiol. 2015;70:476-86.

9. Morris PD, Ryan D, Morton AC, Lycett R, Lawford P, Hose DR, Gunn JP. Virtual fractional flow reserve from coronary angiography: modeling the significance of coronary lesions: results from the VIRTU-1 (VIRTUal Fractional Flow Reserve From Coronary Angiography) study. JACC Cardiovasc Interv. 2013;6: 149-57.

10. Tu S, Barbato E, Köszegi Z, Yang J, Sun Z, Holm NR, Tar B, Li Y, Rusinaru D, Wijns W, Reiber JH. Fractional flow reserve calculation from 3-dimensional quantitative coronary angiography and TIMI frame count: a fast computer model to quantify the functional significance of moderately obstructed coronary arteries. JACC Cardiovasc Interv. 2014;7:768-77.

11. Collet C, Grundeken J, Asano T, Onuma Y, Wijns W, Serruys PW. State of the art: coronary angiography. EuroIntervention. 2017;13: 634-43.

12. Young DF, Tsai FY. Flow characteristics in models of arterial stenosis. I. Steady flow. J Biomech. 1973;6:395-410.

13. Gould KL, Kelley KO, Bolson EL. Experimental validation of quantitative coronary arteriography for determining pressureflow characteristics of coronary stenosis. Circulation. 1982;66: 930-7.

14. Brown BG, Bolson E. Frimer M, Dodge HT. Quantitative coronary arteriography: estimation of dimensions, hemodynamic resistance, and atheroma mass of coronary artery lesions using the arteriogram and digital computation. Circulation. 1977;55: 329-37.

15. Di Mario C, Gil R, de Feyter PJ, Schuurbiers JC, Serruys PW. Utilization of translesional hemodynamics: comparison of pressure and flow methods in stenosis assessment in patients with coronary artery disease. Cathet Cardiovasc Diagn. 1996;38:189-201.

16. Joye JD, Schulman DS. Clinical application of coronary flow reserve using an intracoronary Doppler guide wire. Cardiol Clin. 1997; 15:101-29. 
17. Barbato E, Aarnoudse W, Aengevaeren WR, Werner G, Klauss V, Bojara W, Herzfeld I, Oldroyd KG, Pijls NH, De Bruyne B; Week 25 study group. Validation of coronary flow reserve measurements by thermodilution in clinical practice. Eur Heart J. 2004;25:219-23.

18. Gibson CM, Cannon CP, Daley WL, Dodge JT Jr, Alexander B Jr, Marble SJ, McCabe CH, Raymond L, Fortin T, Poole WK. TIMI frame count: a quantitative method of assessing coronary artery flow. Circulation. 1996;93:879-88.

19. Tu S, Westra J, Yang J, von Birgelen C, Ferrara A, Pellicano M, Nef H, Tebaldi M, Murasato Y, Lansky A, Barbato E, van der Heijden LC, Reiber JH, Holm NR, Wijns W; FAVOR Pilot Trial Study Group. Diagnostic Accuracy of Fast Computational Approach to Derive Fractional Flow Reserve From Diagnostic Coronary Angiography: The International Multicenter FAVOR Pilot Study. JACC Cardiovasc Interv. 2016;19:2024-35.

20. Stoel MG, Zijlstra F, Visser CA. Frame count reserve. Circulation. 2003;107:3034-9.

21. Koszegi Z, Tar B, Ember S, Lugosi P, Beres Z, Santa J, Svab M, Bakk S, Kolozsvari R, Polgar P. Calculation the translesional pressure gradients on coronary stenosis by combining threedimensional coronary angiography parameters with frame count data. Computing in Cardiology. 2011;38:729-32.

22. Kopanidis A, Pantos I, Theodorakakos A, Tzanalaidou E, Katritsis D. Fractional flow reserve derived from conventional coronary angiograms and computational fluid dynamics. Int $J$ Cardiol. 2015;190:187-9.
23. Papafaklis MI, Muramatsu T, Ishibashi Y, Lakkas LS, Nakatani S, Bourantas CV, Ligthart J, Onuma Y, EchavarriaPinto M, Tsirka G, Kotsia A, Nikas DN, Mogabgab O, van Geuns RJ, Naka KK, Fotiadis DI, Brilakis ES, Garcia-Garcia HM, Escaned J, Zijlstra F, Michalis LK, Serruys PW. Fast virtual functional assessment of intermediate coronary lesions using routine angiographic data and blood flow simulation in humans: comparison with pressure wire - fractional flow reserve. EuroIntervention. 2014;10:574-83.

24. Tröbs M, Achenbach S, Röther J, Redel T, Scheuering M, Winneberger D, Klingenbeck K, Itu L, Passerini T, Kamen A, Sharma P, Comaniciu D, Schlundt C. Comparison of Fractional Flow Reserve Based on Computational Fluid Dynamics Modeling Using Coronary Angiographic Vessel Morphology Versus Invasively Measured Fractional Flow Reserve. Am J Cardiol. 2016; 117:29-35.

\section{Supplementary data}

Supplementary Table 1. Comparison of FFR ${ }_{\text {sim }}$ to previous models for virtual FFR computations.

Supplementary Figure 1. Administration of ic. adenosine followed by physiological $\mathrm{NaCl}$ flush and contrast injection.

Supplementary Figure 2. Computation of $\mathrm{FFR}_{\text {sim }}$ in Excel.

The supplementary data are published online at:

http://www.pcronline.com/

eurointervention/141st issue/167 


\section{Supplementary data}

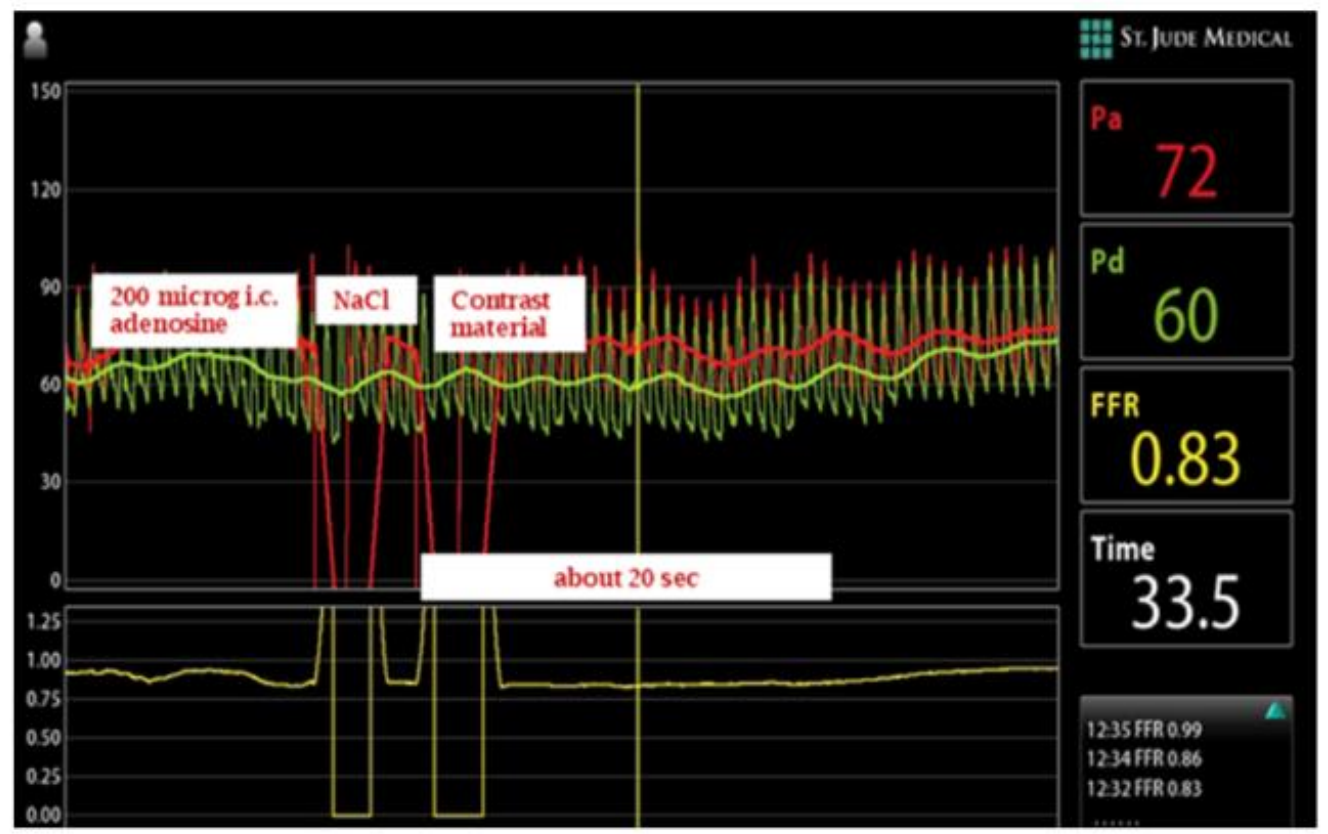

Supplementary Figure 1. Administration of ic. adenosine followed by physiological $\mathrm{NaCl}$ flush and contrast injection. 


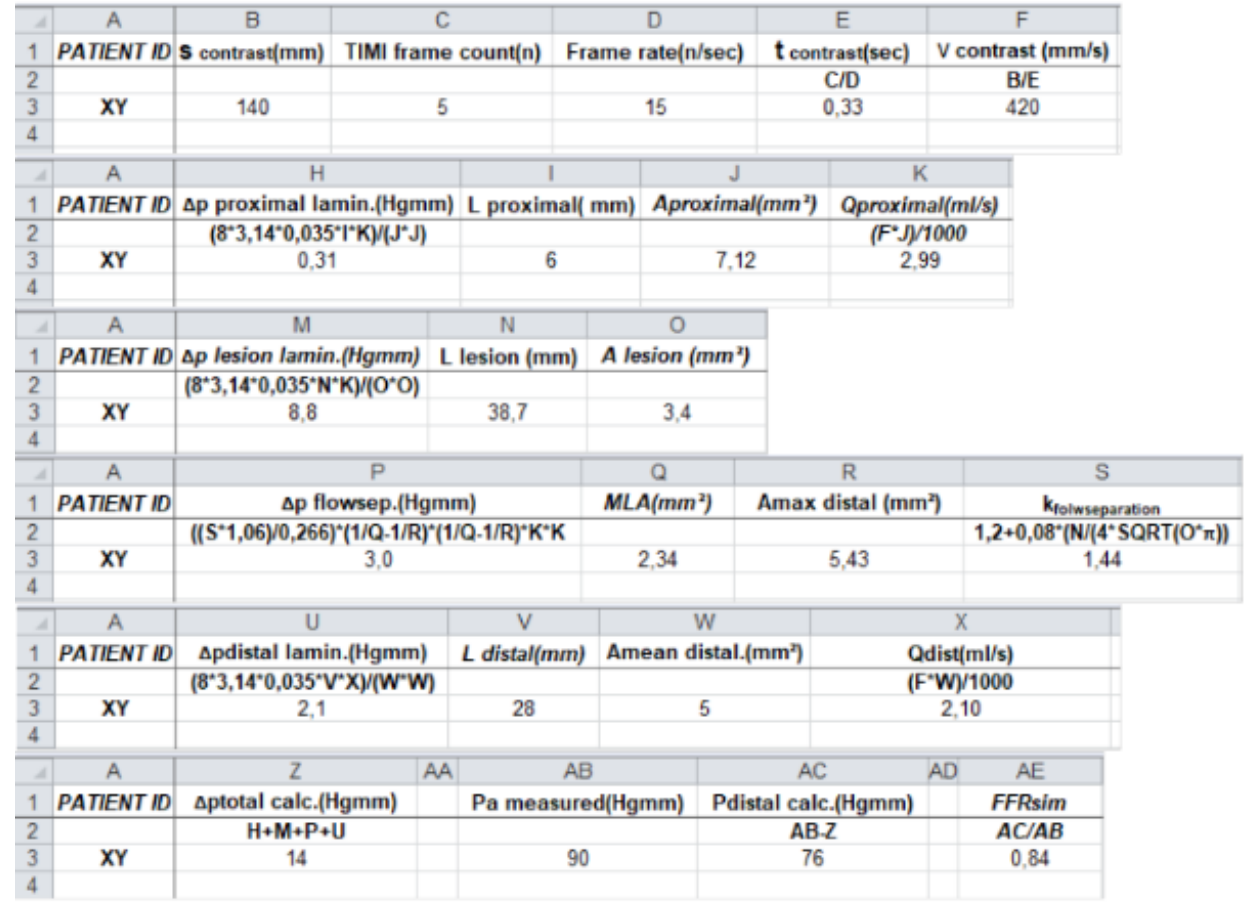

Supplementary Figure 2. Computation of FFR sim $_{\text {in }}$ Excel. 


\section{Supplementary Table 1. Comparison of FFR sim $_{\text {to }}$ previous models for virtual FFR}

computations.

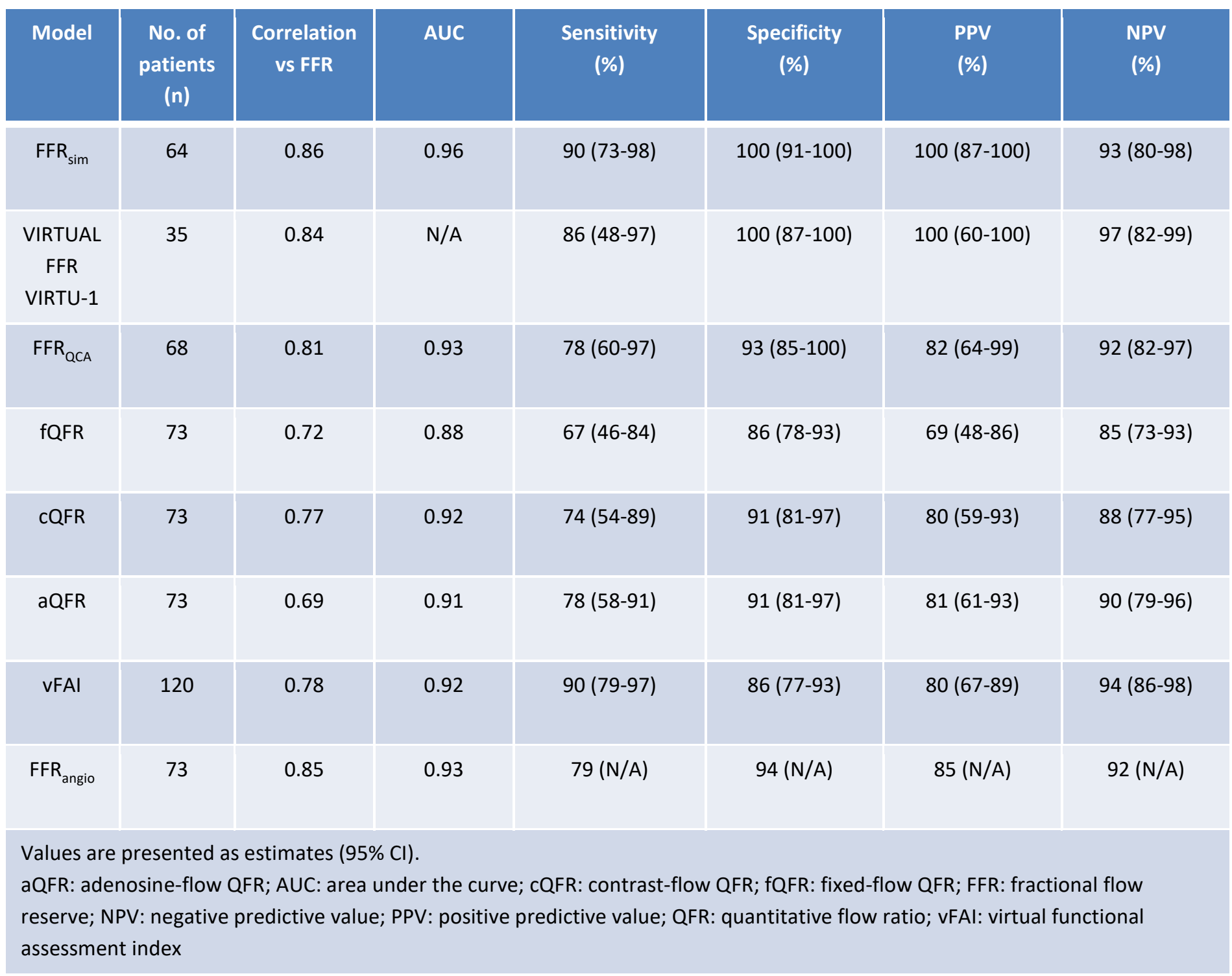

